\title{
The age-related changes and sex difference in master swimming performance
}

\author{
Beat Knechtle $\mathrm{e}^{1,2, *}$, Tiago M. Barbosa ${ }^{3,4,5}$, and Pantelis Theo Nikolaidis ${ }^{6,7}$ \\ 1 Medbase St. Gallen Am Vadianplatz, St. Gallen, Switzerland \\ 2 Institute of Primary Care, University of Zurich, Zurich, Switzerland \\ 3 National Institute of Education, Nanyang Technological University, Singapore, Singapore \\ ${ }^{4}$ Polytechnic Institute of Bragança, Bragança, Portugal \\ ${ }^{5}$ Research Centre in Sports, Health and Human Development, Vila Real, Portugal \\ ${ }^{6}$ Exercise Physiology Laboratory, Nikaia, Greece \\ 7 School of Health and Caring Sciences, University of West Attica, Athens, Greece
}

Received 13 January 2019, Accepted 14 May 2019

\begin{abstract}
Master athletes have been widely used to examine the age-induced decline of human performance. However, so far very limited reviews are available consolidating the age-related differences in master swimming performance. The aim of the present review was to summarize existing knowledge about the age-related changes in three modalities of swimming performance (i.e., pool-swimming, open-water swimming and swim split in triathlons of different distances). In addition, the paradigm of freestyle swimming records from 50 to $1500 \mathrm{~m}$ was used to examine age-related differences and sex difference in performance for age groups 25-29 to 100-104 years. For this example of master freestyle swimmers, the sex difference was smaller in the longer events and increased significantly after the age of $\sim 70$ years. In summary, master athletes competing in swimming as single discipline (i.e., pool-swimming and open-water) and in triathlon (i.e., swim split as first discipline) improved their performances across calendar years. The age-related performance decline in swimming seems to be specific to the discipline, the sex and the length of the swimming event.
\end{abstract}

Key words: aging, aquatic sports, endurance, master athletes, performance, sex

Résumé-Les changements liés à l'âge et la différence de sexe dans la performance de natation chez les athlètes seniors. Les athlètes seniors ont été largement utilisés pour examiner le déclin de la performance humaine induit par l'âge. Cependant, à ce jour, des études très limitées sont disponibles, consolidant les différences de performances de nage des seniors liées à l'âge. Le but de la présente étude était de résumer les connaissances existantes sur les changements liés à l'âge de trois modalités de performance en natation (à savoir, la natation en piscine, la nage en eau libre et la natation divisée en triathlons de différentes distances). De plus, le cas des records de nage libre de 50 à $1500 \mathrm{~m}$ a été utilisé pour examiner les différences liées à l'âge et la différence de performance entre les sexes pour les groupes d'âge partant de 25 à 29 ans jusqu'à 100 à 104 ans. En ce qui concerne le cas des nageurs seniors en eau libre, la différence de sexe était plus petite dans les épreuves plus longues et augmentait significativement après l'âge de 70 ans. En résumé, les athlètes seniors pratiquant la natation en tant que discipline unique (c'est-à-dire la natation en piscine et en eau libre) et le triathlon (c'est-àdire la division en natation comme première discipline) ont amélioré leurs performances au fil des années. La baisse de performance liée à l'âge en natation semble être spécifique à la discipline, au sexe et à la durée de la nage.

Mots clés : vieillissement, sports aquatiques, endurance, athlètes seniors, performance, sexe

\footnotetext{
*Corresponding author: beat.knechtle@hispeed.ch
} 


\section{Introduction}

Competitive swimming is a sports discipline which can be performed in different swim strokes, over different distances and in both pools (i.e., indoor or outdoor) and open water (i.e., sea, lake, river). The different swim strokes are butterfly, backstroke, breaststroke, frontcrawl and the combination of the four strokes as individual medley. In addition to these individual events, four swimmers can take part in either a freestyle or medley relay. In swimming competitions, distances for butterfly, backstroke, breaststroke and freestyle are commonly 50, 100 and $200 \mathrm{~m}$ whereas, individual medley is held over 200 and $400 \mathrm{~m}$. In freestyle swimming, 400, 800 and $1500 \mathrm{~m}$ are additional race distances. In open-water swimming, most often events over 3,5, 10 and $25 \mathrm{~km}$ are held. The 5, 10 and $25 \mathrm{~km}$ are held as official FINA (Fédération Internationale de Natation) races for elite swimmers (Baldassarre, Bonifazi, Zamparo, \& Piacentini, 2017; Veiga, Rodriguez, González-Frutos, \& Navandar, 2019) whereas the $3 \mathrm{~km}$ are especially designed for master swimmers (Knechtle, Nikolaidis, Rosemann, \& Rüst, 2017a).

Swimming is also part of multi-sports races like triathlon (i.e., swimming, cycling and running) over different distances like the Olympic Distance triathlon (i.e., $1.5 \mathrm{~km}$ swimming, $40 \mathrm{~km}$ cycling and $10 \mathrm{~km}$ running), the Half-Ironman (i.e., $1.9 \mathrm{~km}$ swimming, $90 \mathrm{~km}$ cycling and $21.1 \mathrm{~km}$ running), the Ironman (i.e., $3.8 \mathrm{~km}$ swimming, $180 \mathrm{~km}$ cycling, and $42.2 \mathrm{~km}$ running), and longer triathlon distances than the Ironman distance leading to distance of $2 \times, 3 \times, 5 \times$ and $10 \times$ the Ironman distance (Knechtle, Knechtle, \& Lepers, 2011).

A solid body of knowledge has been produced over time about the changes of swimming performance over lifespan. Plenty of research has been carried out on performance impairment by older swimmers (i.e., master swimmers). However, very limited reviews are available consolidating the age-related differences in master swimming performance. In this short review, we summarise recent findings about the age-related performance decline in master swimming. We consider swimming as the single discipline in pool and open-water swimming, but also as one of the three disciplines in triathlon.

For this purpose, the data base PubMed (www.ncbi. nlm.nih.gov/pubmed/) was checked for the term "agerelated performance decline swimming" leading to 42 results. We then extracted all relevant studies for swimming and where swimming was part in a multi-sports discipline event.

\section{The age-related performance decline in general in sport}

It is well-known that performance decreases with increasing age. However, the quantification of the decrease remains to elucidate. For instance, the knowledge of the percentage decrease especially between consecutive age groups would be of great practical value for master athletes.
This decrease seems, however, to depend upon the sport discipline. When track and field athletes were analysed, an accelerated decline beyond the age of 70 years in sprint, middle- and long-distance running was found, while in throwing and jumping disciplines the performance continued a linear decline (Ganse, Ganse, Dahl, \& Degens, 2018). The age-related decline has very often been investigated in triathlon. When the same individual performs in the three disciplines, a smaller age-related decline in cycling performance than in running and swimming performances was observed (Lepers, Knechtle, \& Stapley, 2013).

The distance of an athletic event seems to be crucial for the age-related performance decline. In triathlon, the agerelated performance decline seems to be specific to the race distance (Lepers, Sultana, Bernard, Hausswirth, \& Brisswalter, 2010; Stones \& Hartin, 2017), the type of triathlon event (e.g., Olympic distance, Ironman) (Lepers \& Stapley, 2011) and the discipline (i.e., swimming, cycling and running) (Käch, Rüst, Nikolaidis, Rosemann, \& Knechtle, 2018). When the age-related declines in swimming, cycling, and running performances for both Olympic distance triathlon and Ironman triathlon were compared, the magnitude of the declines in cycling and running performance in the Ironman distance was greater than in the Olympic distance triathlon. The age-related decline in triathlon performance is specific to the discipline, with cycling showing lower declines in performance with age than swimming and running. There was a lesser age-related decline in cycling compared with running and swimming after the age of 55 years in the Olympic distance triathlon and after the age of 50 years in the Ironman distance. With advancing age, the performance decline was less pronounced in the Olympic distance triathlon than in the Ironman triathlon in cycling ( $>55$ years) and running ( $>50$ years). In contrast, an agerelated decline in swimming performance seemed independent of triathlon distance (Lepers, et al., 2010).

However, in triathlon, there seems to be a difference when cycling and running are performed off-road. When the age-related declines in swimming, cycling, and running performances for road-based and off-road triathlons were analysed, there was a less pronounced age-related decline in cycling performance compared to running and swimming for road-based triathlon independently of age. On the other hand, the age-related decline did not differ between the three locomotion modes (i.e., triathlon legs) for off-road triathlon. With advancing age, the performance decline was less pronounced in road-based than offroad triathlon in swimming ( $\geq 65$ years), cycling $(\geq 50$ years), running ( $\geq 60$ years), and overall race time $(\geq 55$ years). These results suggest that the rate of the decline in performance in off-road triathlon is greater than roadbased triathlon, indicating that the type of discipline (i.e., road versus mountain bike cycling and road versus trail running) exerts an important influence on the magnitude of the age-associated changes in triathlon performance (Lepers \& Stapley, 2011).

The age-related performance decline in triathlons seems also specific to the disciplines. For Ironman 
triathletes, the age-related performance decline started in women in age group 25-29 years in swimming and in age group 30-34 years in cycling, running, and overall race time, whereas it started in men in age group $25-29$ years in swimming and in age group 35-39years in cycling, running, and overall race time (Käch, et al., 2018). In Half-Ironman triathlon, the age-related performance decline seems to start in swimming at a higher age compared to the other disciplines. The decline in performance began at a younger cohort age for running (35-39 years) than for swimming ( $50-55$ years) (Stones \& Hartin, 2017).

The age-related decline has also been investigated in competitive swimming, cycling and running as single sports events. The age-related decline in swimming, cycling, and running for endurance and sprint events were investigated (i.e., swimming $1500 \mathrm{~m}$ and $50 \mathrm{~m}$, cycling $1 \mathrm{~h}$ and $200 \mathrm{~m}$, and running $10 \mathrm{~km}$ and $100 \mathrm{~m}$ ). The age-related impairment in $1 \mathrm{~h}$ track cycling was less pronounced than in $1500 \mathrm{~m}$ swimming and in $10 \mathrm{~km}$ running after the age of 60 years. Furthermore, the age-related decline was similar among the three locomotion modes in sprinting events (Lepers, Stapley, \& Cattagni, 2018).

\section{Performance in master athletes}

In recent years, master athletes of old to very old age groups are able to achieve outstanding performances. Today, people older than 90 years old are able to run a marathon (Mueller, Knechtle, Knechtle, \& Toigo, 2014), a 6hour ultra-marathon (Knechtle \& Nikolaidis, 2018) or a 12hour ultra-marathon (Knechtle, Jastrzebski, Rosemann, \& Nikolaidis, 2019). Furthermore, people older than 100 years old are able to cycle during one hour (Lepers, Stapley, \& Cattagni, 2016) or to swim $100 \mathrm{~m}$ backstroke (Unterweger, Knechtle, Nikolaidis, Rosemann, \& Rüst, 2016).

An important aspect in the age-related performance decline is the fact that master athletes improved their performance in recent years in different sports disciplines, also apart from swimming such as athletics (Akkari, Machin, \& Tanaka, 2015; Kundert, Di Gangi, Nikolaidis, \& Knechtle, 2018; Nikolaidis, Zingg, \& Knechtle, 2017; Schneider, Nikolaidis, \& Knechtle, 2018) and triathlon (Gallmann, Knechtle, Rüst, Rosemann, \& Lepers, 2014; Lepers \& Stapley, 2011; Lepers, Rüst, Stapley, \& Knechtle, 2013; Stiefel, Knechtle, \& Lepers, 2014; Wonerow, Rüst, Nikolaidis, Rosemann, \& Knechtle, 2017).

Race times of master athletes competing from 1975 to 2013 in the $100 \mathrm{~m}$ running, the $400 \mathrm{~m}$ running and the $100 \mathrm{~m}$ freestyle swimming events were analysed. Master athletes improved their athletic performance significantly and progressively over the years. The improvements in the fastest $100 \mathrm{~m}$ running times over time were not significant. However, all the masters' age group records improved significantly over time. The slopes of improvements over the years were progressively greater at older age groups with the greatest progression observed at oldest age groups of $75-79$ years old examined. The general trends were similar for $400 \mathrm{~m}$ middle-distance running and $100 \mathrm{~m}$ freestyle swimming events (Akkari, et al., 2015). This improvement might have an impact on the performance decline with increasing age.

An improvement in performance has been especially shown for master triathletes competing in the Olympic distance (Lepers \& Stapley, 2011; Wonerow, et al., 2017) and the Ironman distance (Gallmann, et al., 2014; Lepers, Rüst, et al., 2013) triathlon. For age group triathletes competing in the Olympic distance triathlon at the International Triathlon Union (ITU) World Championships 2009-2014, women and men improved performance in most age groups across all years. Swimming performance improved in athletes in age groups 25-29 years to 55-59 years, but not in younger (i.e., 18-24 years) and older (i.e. $>60-64$ years) age groups. Cycling performance improved in athletes in age groups 18-24 years to 70 74 years, but not in age group 75-79 years. In running, athletes in age groups 18-24 years, 30-34 years, 3539 years and 65-69 years improved, but not in the other age groups. Overall race time was improved by athletes in age groups 18-24 to 65-69 years, but not in age groups 7074 years and 75-79 years (Wonerow, et al., 2017). When changes in participation and performance trends of older (i.e. $>40$ years of age) triathletes competing between 1986 and 2010 in "Ironman Hawaii" were analysed, the relative participation of master triathletes increased while the participation of triathletes younger than 40 years of age decreased. Men older than 44 years old and women older than 40 years old significantly improved their performances in swimming, cycling, running and in overall race time. Sex differences in overall race time decreased in all age groups between the 40-44 and 55-59years old (Lepers, Rüst, et al., 2013). Very unique for "Ironman Hawaii" is the fact the age of annual top 10 female and male triathletes in the "Ironman Hawaii" increased over the last three decades while their performances improved (Gallmann, et al., 2014). Similar findings were reported also in an "Ironman Hawaii" qualifying event. In "Ironman Switzerland", triathletes older than 40 years old significantly improved their performance in swimming, cycling, running split times and in overall race time (Stiefel, et al., 2014).

However, also master swimmers competing at the FINA World Championships in pool- swimming in freestyle (Knechtle, Nikolaidis, Konig, Rosemann, \& Rüst, 2016), in backstroke (Unterweger, et al., 2016), in butterfly (Knechtle, Nikolaidis, Rosemann, \& Rüst, 2017b), in breaststroke (Knechtle, Nikolaidis, Rosemann, \& Rüst, 2016), in individual medley (Nikolaidis \& Knechtle, 2018) and in $3000 \mathrm{~m}$ open-water swimming (Knechtle, et al., 2017a) improved their performances. Although we know that endurance performance decreases with increasing age, the events' distance might be of importance. When the age-related declines in swimming, cycling, running and overall race time for Triple Iron ultratriathlon (i.e., $11.4 \mathrm{~km}$ swimming, $540 \mathrm{~km}$ cycling and $126.6 \mathrm{~km}$ running) and Deca Iron ultra-triathlon (i.e., $38 \mathrm{~km}$ swimming, $1800 \mathrm{~km}$ cycling and $420 \mathrm{~km}$ running) 
were analysed, the fastest overall race times were achieved between the ages of 25 and 44 years old for both distances. However, Deca Iron ultra-triathletes achieved the same level of performance in swimming and cycling between 25 and 54 years of age, which is higher than for shorter race distances. A potential explanation could be the age of the triathletes in the longer race distance because the mean age of the finishers was significantly higher for Deca Iron ultra-triathletes $(41.3 \pm 3.1$ years $)$ compared to a Triple Iron ultra-triathletes (38.5 \pm 3.3 years) (Knechtle, Rüst, Knechtle, Rosemann, \& Lepers, 2012).

\section{The age-related performance decline in pool-swimming}

Also in competitive pool-swimming, the age-related performance decline is well-known (Bongard, McDermott, Dallal, \& Schaefer, 2007; Fairbrother, 2007a, 2007b; Lapierre, Baker, \& Tanaka, 2018; Tanaka \& Seals, 1997) where the decline appears to be associated with the length of the swim distance. Tanaka and Seals (Tanaka \& Seals, 1997) analysed the age-related performance decline in 50 to $1500 \mathrm{~m}$ freestyle swimming by performing a retrospective analysis of top freestyle performance times from the US Masters Swimming Championships. In both men and women, performance in $1500 \mathrm{~m}$ declined linearly from peak levels at the age of 35-40 years old until approximately to the age of 70 years old, whereupon performance declined exponentially thereafter. Performance in $50 \mathrm{~m}$ freestyle showed only a moderate decline until the age of 75 and 80 years in both women and men (Tanaka \& Seals, 1997).

Potential explanations for the slower swimming speed with increasing age are physiological, biomechanical changes and an increase in energy cost of swimming. The decrease in swimming performance with increasing age is a not only consequence of the physiological decrease in maximal metabolic power but can also be expected to depend on an increase in the energy cost of swimming. It has been shown that older master athletes (60-80 years) swam at a significantly slower pace, with a lower propelling efficiency and a larger projected frontal area than younger master athletes (30-60 years) (Zamparo, Dall'ora, Toneatto, Cortesi, \& Gatta, 2012). However, also slowing in swimming is due to biological or behavioural factors affecting physical performance (Fairbrother, 2007b). It is well-known that physiological functional capacity decreased only modestly until the age of 60-70years, but declined exponentially thereafter (Tanaka \& Seals, 2003). A further aspect is training. It has been shown that master athletes spend significantly less time per week training for competition, and their training focus is on endurance, not strength. In contrast, younger swimmers train for endurance, strength, speed, and power, and thus, their performance relies mostly on anaerobic energy transfer systems (Weir, Kerr, Hodges, McKay, \& Starkes, 2002). Moreover, a comparison between "young" masters and elite swimmers indicated that elite differed from master swimmers in terms of their larger anaerobic contribution which was in agreement with their different training characteristics where master's training was mainly characterized by a lower volume and intensity than the elite ones (Mejias, et al., 2014).

When the one-hour swimming performance of 4271 presumably healthy men and women, aged 19-91 years, from the 2001-2003 United States Masters Swimming long-distance $(1 \mathrm{~h})$ national competition were analyzed, the declines in performance were parallel in men and women at all ages, and the 1-year age-related declines in performance were about twice as great at 40 years old and more than four-times as great at 80 years than at 20 years of age (Bongard, et al., 2007). This finding is similar to the age-related performance decline in master swimmers competing in freestyle, the swimming speed in the age group world records from 25-29 to 100-104 age-groups shows a non-linear decrease for all distances (Fig. 1). Interestingly, only women were able to swim in age group 100-104 years in the longer freestyle distances (i.e., 200 to $1500 \mathrm{~m})$.

\section{The age-related performance decline in open-water swimming}

For open-water swimming, the age-related performance decline has mainly been investigated for the swim split in triathlon races of different distances such as Olympic distance and Ironman distance.

It seems that differences do exist between the different distances. The age-related decline in triathlon performance seems to be specific to the discipline, with cycling showing fewer declines in performance with age than swimming and running. When swimming, cycling, running and overall race times of the top 10 males between 20 and 70 years of age were analysed in 5-years-intervals for two consecutive World championships (2006 and 2007) for Olympic and Ironman distances, a less pronounced agerelated decline in cycling performance compared with running and swimming after the age of 55 years for Olympic distance and after the age of 50 years for Ironman distance was found. With advancing age, the performance decline was less pronounced for Olympic than for Ironman triathlon in cycling ( $>55$ years) and running ( $>50$ years), respectively. In contrast, an age-related decline in swimming performance seemed independent of triathlon distance (Lepers, et al., 2010).

There also seem to exist differences between the sexes regarding the age-related performance decline for the different distances. In Olympic distance triathlon, the agerelated declines in performance were significantly less pronounced for males compared with females for swimming (>50years), for cycling ( $>40$ years) and for overall race time (> 40 years) (Etter, Knechtle, Rüst, Rosemann, \& Lepers, 2013). For Ironman triathletes, the age-related decline in performance started earlier in swimming than in cycling and running. In women, the age-related performance decline started in age group 25-29years in 

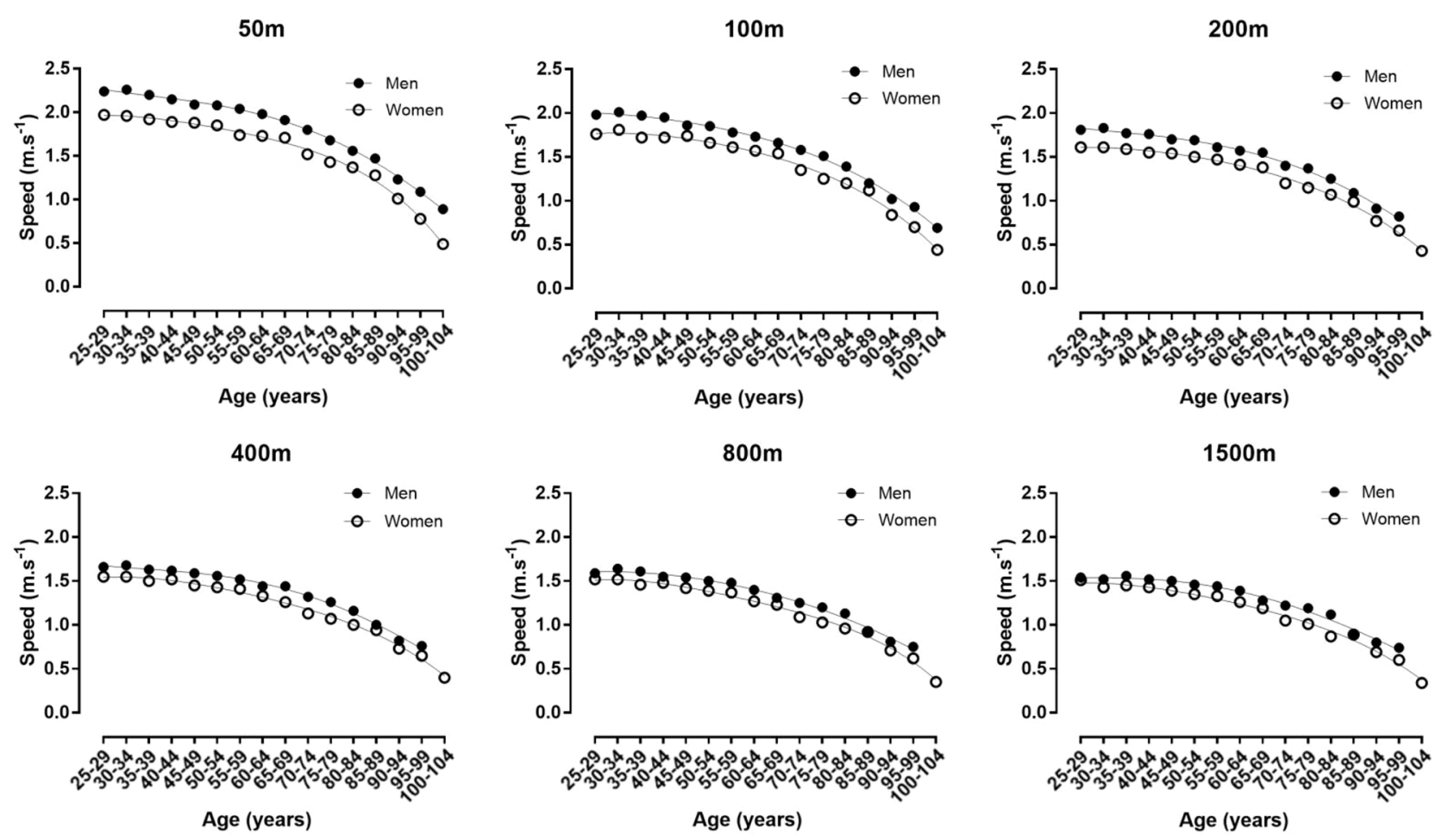

Fig. 1. Speed in freestyle swimming by age group (from 25-29 to 100-104 years) and distance (50-1500 m) in men and women. The figure is drawn with data on master world records from http://archives.fina.org/database/main/records.php (access date 1/11/2018). $R^{2}$ coefficient of determination for fourth degree polynomial regression ranged from 0.99 to 1.00 . The figure was created using GraphPad Prism v. 7.0 (GraphPad Software, San Diego, USA).

swimming and in age group 30-34 years in cycling, running, and overall race time, whereas it started in men in age group $25-29$ years in swimming and in age group 35-39 years in cycling, running, and overall race time (Käch, Rüst, Nikolaidis, Rosemann, \& Knechtle, 2018).

\section{Sex difference in the age-related performance decline}

Differences between women and men regarding the agerelated performance decline have been described. For example, in track and field athletes, the steepest declines were observed in javelin throw and $400 \mathrm{~m}$ for women and in pole vault and $800 \mathrm{~m}$ for men (Ganse, et al., 2018). When the differences in performance between women and men and changes in performance in selected age categories at the ITU Cross World Championships held between 2011 and 2016 were analysed, the best results in cycling and total race time were obtained in age group 30-34 years-old and in swimming and running in age group 40-44 years old in men. Women, however, obtained the best results in running in age group 25-29years, in cycling in age group 30-34 years, and in both swimming and overall race time in age group 35-39 years (Romero-Ramos, Fernández-Rodríguez, Merino-Marbán, Mayorga-Vega, \& Podstawski, 2018).

Tanaka \& Seals (1997) analysed the age-related performance decline in 50 to $1500 \mathrm{~m}$ freestyle swimming by performing a retrospective analysis of top freestyle performance times from the US Masters Swimming Championships and showed that the decrease was linear until the age of $\sim 70-80$ years old whereupon the decline becomes exponential. Moreover, the rate of decline with advancing age appears to be associated with event's duration and sex. The percent of sex difference in performance throughout the age range studied became progressively smaller with increasing distance from $50 \mathrm{~m}$ $(19 \pm 1 \%)$ to $1500 \mathrm{~m}(11 \pm 1 \%)$. The rate and magnitude of the declines in both 50 and $1500 \mathrm{~m}$ swimming performance with age were significantly greater in women than in men. In the women, the percent decline in swimming performance over 50 years old from the age group 19-24 years to age group 69-74 years became progressively greater from the 50 to the $1500 \mathrm{~m}$; whereas in men, no differences were observed in the magnitude of performance decline with age among the five longest distance events (i.e., 100 to $1500 \mathrm{~m}$ ) (Tanaka \& Seals, 1997).

When we consider the sex difference in performance in freestyle swimming from 50 to $1500 \mathrm{~m}$ for the master world records (Fig. 2), the sex difference increases in a non-linear fashion-way in both 50 and $100 \mathrm{~m}$ after the age of 90 years; whereas in longer distances (i.e., 200 to $1500 \mathrm{~m}$ ), sex difference increases rather linearly. There is, however, also a sex difference in swimming when swimming is the first discipline in a triathlon. In Olympic distance triathletes, the age-related declines in performance were significantly less pronounced for males compared with females for swimming ( $>50$ years), for cycling ( $>40$ years) 


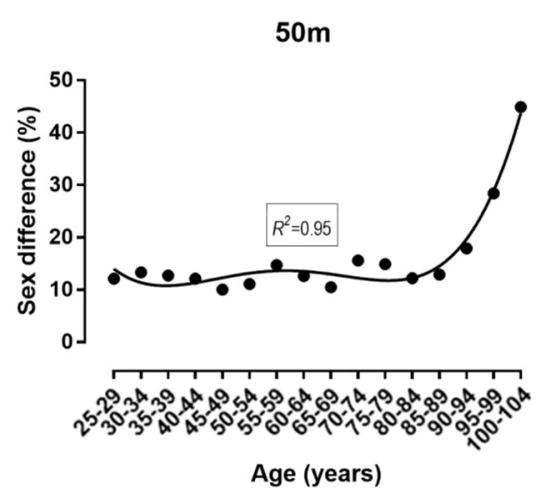

$400 \mathrm{~m}$

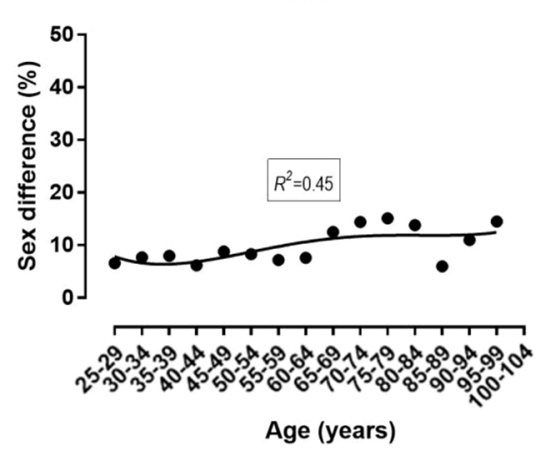

$100 \mathrm{~m}$

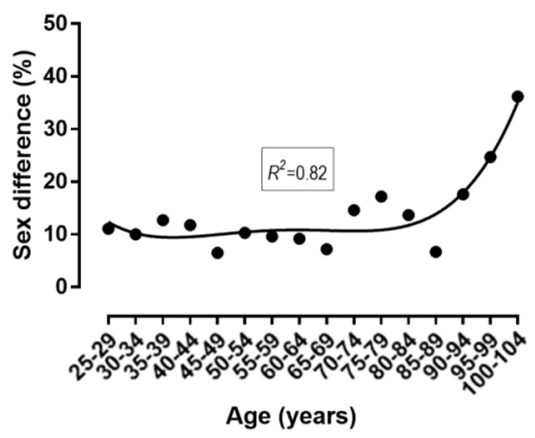

$800 \mathrm{~m}$

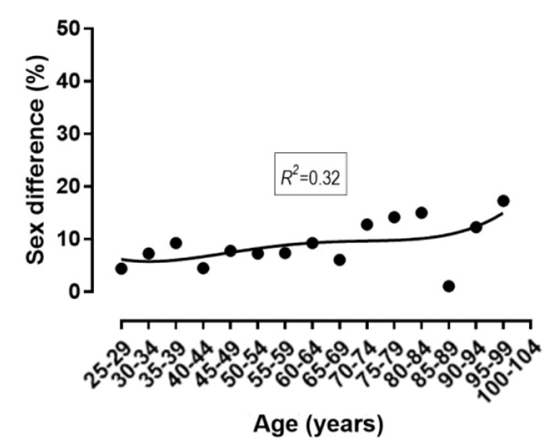

$200 \mathrm{~m}$

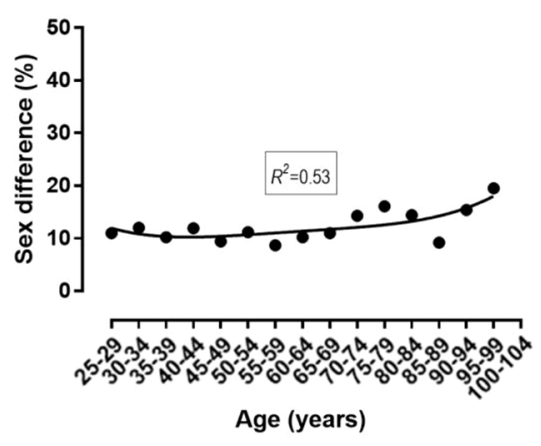

$1500 \mathrm{~m}$

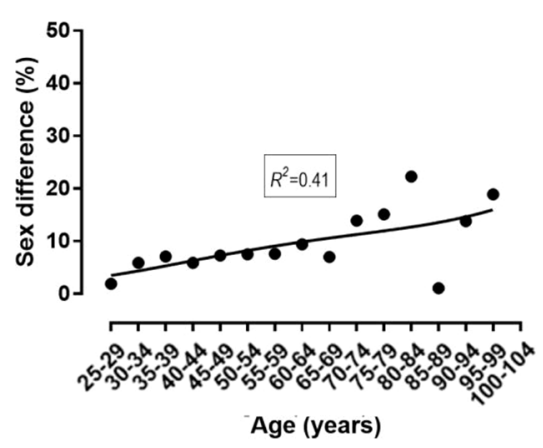

Fig. 2. Sex difference in speed in freestyle swimming by age group (from 25-29 to 100-104 years) and distance (50-1500 m) in men and women. The figure is drawn with data on master world records from http://archives.fina.org/database/main/records.php (access date $1 / 11 / 2018) . R^{2}$ coefficient of determination refers to fourth degree polynomial regression. The sex difference was calculated using the formula " $100 \times($ speed in men - speed in women)/speed in women". The figure was created using GraphPad Prism v. 7.0 (GraphPad Software, San Diego, USA).

and for overall race time ( $>40$ years) (Etter, Knechtle, Rüst, Rosemann, \& Lepers, 2013).

Studies investigated the sex difference in performance in master swimmers competing at the FINA World Championships in pool swimming in freestyle (Knechtle, Nikolaidis, Konig et al., 2016), backstroke (Unterweger, et al., 2016), butterfly (Knechtle et al., 2017b), breaststroke (Knechtle, Nikolaidis, Rosemann et al., 2016), individual medley (Nikolaidis \& Knechtle, 2018) and in 3000 m openwater swimming (Knechtle, et al., 2017a). When age groups 25-29 to 90-94 years competing at the FINA World Masters Championships between 1986 and 2014 were analyzed, in older age groups, women were able to achieve a similar performance to men. In freestyle events, women were slower than men in age groups $25-29$ to $75-79$ years, but not in the age groups 80-84 and 85-89 years. In 50, 100 and $200 \mathrm{~m}$, women reduced the sex difference in age groups 30-34 to 75-79 years. In $400 \mathrm{~m}$, women reduced the gap to men in age groups 40-44, 45-49, and 55-59 years. In $800 \mathrm{~m}$, sex difference became reduced in age groups $55-59$ and $70-$ 74 years (Knechtle, Nikolaidis, Konig et al., 2016). In backstroke swimming, women were slower than men in age groups 25-29 to 80-84 years, but not in age groups 85-89 to 95-99 years over all distances. In 50 and $100 \mathrm{~m}$, the sex difference decreased in age groups 40-44, 45-49, 50-54, and
55-59 years. In $200 \mathrm{~m}$, the sex difference decreased in age groups 40-44 and 90-94 years, but increased in age group 25-29 years (Unterweger, et al., 2016). In butterfly swimming, men were faster than women from 25-29 to 85-89 years but not for 90-94 years. Women were able to reduce the sex difference in performance in several age groups. In $50 \mathrm{~m}$ butterfly, women reduced the sex difference in age groups $30-34$ to $60-64$ years. In $100 \mathrm{~m}$ butterfly, women decreased the gap to men in age groups 35-39 to 5559 years. In $200 \mathrm{~m}$, the sex difference was reduced in age groups 30-34 to 40-44 years (Knechtle, et al., 2017b). In breaststroke swimming, men were not faster than women age groups 90-94 to 95-99 years. In $50 \mathrm{~m}$, women reduced the gap to men in age groups 40-44 to 70-74 years. In both 100 and $200 \mathrm{~m}$, women reduced the gap in age groups 50-54 to 60-64 years (Knechtle, Nikolaidis, Rosemann, et al., 2016). In 200 and $400 \mathrm{~m}$ individual medley, men were faster than women from 25-29 to 80-84 years, but not in 85-90 and 90-94 years. Women reduced the gap to men in 40-44 and 45-49years in $200 \mathrm{~m}$, and 40-44years in $400 \mathrm{~m}$ (Nikolaidis \& Knechtle, 2018). Finally, in $3000 \mathrm{~m}$ openwater swimming, women were slower in age groups $25-29$ to 70-74 years. In age groups 75-79 and 85-89 years, however, race times were similar for both women and men (Knechtle, et al., 2017a). 
A potential explanation for the improved performance in elderly women is the fact that peak performance ages in women have increased significantly since 1980s. When 118 years from the first Olympics (1896) to the most recent Olympics (2014) were analysed regarding the ages at which peak performance was observed, peak performance ages in women have increased significantly since 1980s and consistently in all the athletic events examined (i.e., track and field, swimming, rowing, and ice skating events). Interestingly, as women's peak performance age increased, they became similar to men's peak ages in many events. In the last 20 30 years, ages at which peak athletic performance is observed have increased in women but not in men (Elmenshawy, Machin, \& Tanaka, 2015). In addition, biomechanical differences between women and men would partially explain sex differences in the age-related decline of performance (Ferreira, et al., 2015; Seifert, Barbosa, \& Kjendlie, 2011).

\section{Conclusion}

In summary, master athletes competing in swimming as single discipline (i.e., pool-swimming and open-water) and in triathlon (i.e., swim split as first discipline) improved their performances across calendar years. The age-related performance decline in swimming seems to be specific to the discipline, the sex and the length of the swimming event.

\section{Author contributions}

All authors contributed equally to the paper.

\section{References}

Akkari, A., Machin, D., \& Tanaka, H. (2015). Greater progression of athletic performance in older Masters athletes. Age and Ageing, 44(4), 683-686.

Baldassarre, R., Bonifazi, M., Zamparo, P., \& Piacentini, M.F. (2017). Characteristics and challenges of open-water swimming performance: A review. International Journal of Sports Physiology and Performance, 12(10), 1275-1284.

Bongard, V., McDermott, A.Y., Dallal, G.E., \& Schaefer, E.J. (2007). Effects of age and gender on physical performance. Age (Dordrecht, Netherlands), 29(2-3), 77-85.

Elmenshawy, A.R., Machin, D.R., \& Tanaka, H. (2015). A rise in peak performance age in female athletes. Age (Dordrecht, Netherlands), 37(3), 9795.

Etter, F., Knechtle, B., Rüst, C.A., Rosemann, T., \& Lepers, R. (2013). The age-related decline in Olympic distance triathlon performance differs between males and females. Journal of Sport Medicine and Physical Fitness, 53(3), 261-267.

Fairbrother, J.T. (2007a). Age-related changes in top-ten men's U.S. Masters 50-m freestyle swim times as a function of finishing place. Perceptual and Motor Skills, 105(3 Pt 2), 1289-1293.

Fairbrother, J.T. (2007b). Prediction of 1500-m freestyle swimming times for older masters all-American swimmers. Experimental Aging Research, 33(4), 461-471.

Ferreira, M.I., Barbosa, T.M., Neiva, H.P., Marta, C.C., Costa, M.J., \& Marinho, D.A. (2015). Effect of gender, energetics, and biomechanics on swimming masters performance. Journal of Strength and Conditioning Research, 29(7), 1948-1955.
Gallmann, D., Knechtle, B., Rüst, C.A., Rosemann, T., \& Lepers, R. (2014). Elite triathletes in "Ironman Hawaii" get older but faster. Age (Dordrecht, Netherlands), 36(1), 407-416.

Ganse, B., Ganse, U., Dahl, J., \& Degens, H. (2018). Linear decrease in athletic performance during the human life span. Frontiers in Physiology, 9, 1100.

Käch, I.W., Rüst, C.A., Nikolaidis, P.T., Rosemann, T., \& Knechtle, B. (2018). The age-related performance decline in Ironman triathlon starts earlier in swimming than in cycling and running. Journal of Strength and Conditioning Research, 32(2), 379-395.

Knechtle, B., \& Nikolaidis, P.T. (2018). Pacing in a 94-year-old runner during a 6-hour run. Open Access Journal of Sports Medicine, 9, 19-25.

Knechtle, B., Knechtle, P., \& Lepers, R. (2011). Participation and performance trends in ultra-triathlons from 1985 to 2009. Scandinavian Journal of Medicine 6 Science in Sports, 21, e82-90.

Knechtle, B., Rüst, C.A., Knechtle, P., Rosemann, T., \& Lepers, R. (2012). Age-related changes in ultra-triathlon performances. Extreme Physiology $\& 5$ Medicine, 1(1), 5.

Knechtle, B., Nikolaidis, P.T., Konig, S., Rosemann, T., \& Rüst, C.A. (2016). Performance trends in master freestyle swimmers aged 25-89 years at the FINA World Championships from 1986 to 2014. Age (Dordrecht, Netherlands), 38(1), 18.

Knechtle, B., Nikolaidis, P.T., Rosemann, T., \& Rüst, C.A. (2016). Performance trends in age group breaststroke swimmers in the FINA World Championships 1986-2014. Chinese Journal of Physiology, 59(5), 247-259.

Knechtle, B., Nikolaidis, P.T., Rosemann, T., \& Rüst, C.A. (2017a). Performance trends in $3000 \mathrm{~m}$ open-water age group swimmers from 25 to 89 years competing in the FINA World Championships from 1992 to 2014. Research in Sports Medicine, 25(1), 67-77.

Knechtle, B., Nikolaidis, P.T., Rosemann, T., \& Rüst, C.A. (2017b). Performance trends in master butterfly swimmers competing in the FINA World Championships. Journal of Human Kinetics, 57, 199-211.

Knechtle, B., Jastrzebski, Z., Rosemann, T., \& Nikolaidis, P.T. (2019). Pacing during and physiological response after a 12hour ultra-marathon in a 95-year-old male runner. Frontiers in Physiology, 9, 1875.

Kundert, A.M.L., Di Gangi, S., Nikolaidis, P.T., \& Knechtle, B. (2018). Jumping and throwing performance in the World Masters' Athletic Championships 1975-2016. Research in Sports Medicine, 27, 374-411.

Lapierre, S.S., Baker, B.D., \& Tanaka, H. (2018). Age-related changes in training stimuli and performance in masters swimmers. International Journal of Sports Medicine, 39(11), 835-839.

Lepers, R., \& Stapley, P.J. (2011). Age-related changes in conventional road versus off-road triathlon performance. European Journal of Applied Physiology, 111(8), 1687-1694.

Lepers, R., Sultana, F., Bernard, T., Hausswirth, C., \& Brisswalter, J. (2010). Age-related changes in triathlon performances. International Journal of Sports Medicine, 31 (4), 251-256.

Lepers, R., Knechtle, B., \& Stapley, P.J. (2013). Trends in triathlon performance: Effects of sex and age. Sports Medicine, 43(9), 851-863.

Lepers, R., Rüst, C.A., Stapley, P.J., \& Knechtle, B. (2013). Relative improvements in endurance performance with age: Evidence from 25 years of Hawaii Ironman racing. Age (Dordrecht, Netherlands), 35(3), 953-962.

Lepers, R., Stapley, P.J., \& Cattagni, T. (2016). Centenarian athletes: Examples of ultimate human performance? Age and Ageing, 45(5), 732-736. 
Lepers, R., Stapley, P.J., \& Cattagni, T. (2018). Variation of agerelated changes in endurance performance between modes of locomotion in men: An analysis of Master World Records. International Journal of Sports Physiology and Performance, 13(3), 394-397.

Mejias, J.E., Bragada, J.A., Costa, M.J., Reis, V.M., Garrido, N.D. \& Barbosa, T.M. (2014). "Young" masters vs. Elite swimmers: Comparison of performance, energetics, kinematics and efficiency. International SportMed Journal, 15(2), 165-177.

Mueller, S.M., Knechtle, B., Knechtle, P., \& Toigo, M. (2014). Physiological alterations after a marathon in the first 90-yearold male finisher: Case study. Springerplus, 3, 608.

Nikolaidis, P.T., \& Knechtle, B. (2018). Performance trends in individual medley events during FINA World Master Championships from 1986 to 2014. The Journal of Sports Medicine and Physical Fitness, 58(5), 690-698.

Nikolaidis, P.T., Zingg, M.A., \& Knechtle, B. (2017). Performance trends in age-group runners from $100 \mathrm{~m}$ to marathon-The World Championships from 1975 to 2015. Scandinavian Journal of Medicine 63 Science in Sports, 27 (12), 1588-1596.

Romero-Ramos, O., Fernández-Rodríguez, E., Merino-Marbán, R., Mayorga-Vega, D., \& Podstawski, R. (2018). Age and gender differences in performance at cross triathlon world championships. Polish Journal of Sport and Tourism, 25(3), 17-22.

Schneider, A.L., Nikolaidis, P.T., \& Knechtle, B. (2018). Improved performance in master runners competing in the European Championships between 1978 and 2014. Journal of Strength and Conditioning Research. doi: 10.1519/ jsc.0000000000002548.

Seifert, L., Barbosa, T., \& Kjendlie, P.L. (2011). Biophysical approach in swimming: Gender effect. In S.A. Davies (Ed.), Gender gap: Causes, experiences and effects (pp. 59-80). Nova Science Publishers, Inc.

Stiefel, M., Knechtle, B., \& Lepers, R. (2014). Master triathletes have not reached limits in their Ironman triathlon performance. Scandinavian Journal of Medicine 8 Science in Sports, 24(1), 89-97.
Stones, M.J., \& Hartin, A. (2017). Aging and half-Ironman performance. Experimental Aging Research, 43(2), 178-191.

Tanaka, H., \& Seals, D.R. (1997). Age and gender interactions in physiological functional capacity: Insight from swimming performance. Journal of Applied Physiology (1985), 82(3), 846-851.

Tanaka, H., \& Seals, D.R. (2003). Invited review: Dynamic exercise performance in Masters athletes: Insight into the effects of primary human aging on physiological functional capacity. Journal of Applied Physiology (1985), 95(5), 2152-2162.

Unterweger, C.M., Knechtle, B., Nikolaidis, P.T., Rosemann, T., \& Rüst, C.A. (2016). Increased participation and improved performance in age group backstroke master swimmers from 25-29 to 100-104 years at the FINA World Masters Championships from 1986 to 2014. Springerplus, 5, 645.

Veiga, S., Rodriguez, L., González-Frutos, P., \& Navandar, A. (2019). Race strategies of open water swimmers in the $5-\mathrm{km}$, $10-\mathrm{km}$, and $25-\mathrm{km}$ races of the 2017 FINA World Swimming Championships. Frontiers in Psychology, 10: 654. eCollection 2019.

Weir, P.L., Kerr, T., Hodges, N.J., McKay, S.M., \& Starkes, J.L. (2002). Master swimmers: How are they different from younger elite swimmers? An examination of practice and performance patterns. Journal of Aging and Physical Activity, 10(1), 41-63.

Wonerow, M., Rüst, C.A., Nikolaidis, P.T., Rosemann, T., \& Knechtle, B. (2017). Performance trends in age group triathletes in the Olympic Distance Triathlon at the World Championships 2009-2014. Chinese Journal of Physiology, 60 (3), 137-150.

Zamparo, P., Dall'ora, A., Toneatto, A., Cortesi, M., \& Gatta, G. (2012). The determinants of performance in master swimmers: A cross-sectional study on the age-related changes in propelling efficiency, hydrodynamic position and energy cost of front crawl. European Journal of Applied Physiology, 112(12), 3949-3957.

Cite this article as: Knechtle B, Barbosa TM, \& Nikolaidis PT (2019) The age-related changes and sex difference in master swimming performance. Mov Sport Sci/Sci Mot, 104, 29-36 